\title{
Gamechangers in het Europees privaatrecht
}

\author{
Prof. mr. H.N. Schelhaas en mr.drs. D.F.H. Stein*
}

De laatste twee jaar vonden twee belangrijke jubilea plaats waar grote gebeurtenissen van het Nederlandse privaatrecht werden gememoreerd. In de eerste plaats werd in 2017 het 25jarig bestaan van het Burgerlijk Wetboek (BW) gevierd. ${ }^{1}$ De inwerkingtreding van het $\mathrm{BW}$ was indertijd inderdaad een grote gebeurtenis, die het Nederlandse burgerlijk recht op diverse punten substantieel heeft veranderd. In de tweede plaats werd begin dit jaar herdacht ${ }^{2}$ dat 100 jaar geleden het arrest Lindenbaum/Cohen ${ }^{3}$ werd gewezen, een arrest dat een grote invloed heeft gehad op de ontwikkeling van het onrechtmatigedaadrecht in Nederland. In beide gevallen ging het om belangrijke nationale gebeurtenissen: de inwerkingtreding van een nieuw Nederlands Burgerlijk Wetboek en een arrest van de Hoge Raad der Nederlanden. Beide gebeurtenissen hebben de ontwikkeling van het Nederlandse privaatrecht in de loop der jaren aanzienlijk beïnvloed en hebben de privaatrechtelijke (spel)regels in Nederland veranderd.

Het is een gemeenplaats dat het Nederlandse privaatrecht niet alleen wordt ontwikkeld door nationale keuzes van de wetgever of nationale rechtspraak, maar ook en in toenemende mate door internationale ontwikkelingen. Geïnspireerd door de hiervoor genoemde twee gamechangers van het Nederlandse privaatrecht, gaan wij in dit themanummer op zoek naar Europese gamechangers, die óók het Nederlandse privaatrecht (zouden kunnen) hebben beïnvloed. Meer specifiek bespreken wij Europese ontwikkelingen die voortvloeien uit het EU-recht of het EVRM en die de bestaande privaat-

\footnotetext{
Prof. mr. H.N. Schelhaas is hoogleraar privaatrecht aan de Erasmus Universiteit Rotterdam en redacteur van dit blad. Mr. drs. D.F.H. Stein is promovendus en docent Burgerlijk recht aan de Radboud Universiteit Nijmegen, verbonden aan het Onderzoekcentrum Onderneming \& Recht (OO\&R) en redacteur van dit blad.

1. Hier werd onder meer aandacht an besteed in een symposium, georganiseerd door het Ministerie van Veiligheid en Justitie www.rijksoverheid.nl/actueel/nieuws/2017/11/22/congres\%E2\%80\%9825-jaar-nieuw-bw-met-het-oog-op-de-toekomst $\% \mathrm{E} 2 \% 80 \% 99)$, waarvan de bijdragen zijn gepubliceerd in NJB 2018/1238, afl. 25. Verder wijdde het WPNR hier een themanummer aan (WPNR 2017/7133) en werd ook in dit tijdschrift aandacht besteed aan het 25-jarig bestaan van het BW: H.J. Snijders, NBW-vermogensrecht 25 jaar, MvV 2017, afl. 12, p. 317-320.

2. Zie het op 31 januari 2019 gehouden congres: www.rechtspraak.nl/ Organisatie-en-contact/Organisatie/Hoge-Raad-der-Nederlanden/ Nieuws/Paginas/Honderd-jaar-arrest-Lindenbaum-Cohen-arrestgepubliceerd-op-rechtspraaknl.aspx. Zie ook de speciaal hieraan gewijde bijdragen in RM Themis 2019, afl. 1.

3. HR 31 januari 1919, ECLI:NL:HR:1919:AG1776, NJ 1919, p. 161.
}

rechtelijke situatie drastisch hebben veranderd. Acht auteurs bespreken vanuit verschillende invalshoeken dergelijke gamechangers, analyseren de invloed die zij hebben gehad op het Nederlandse en Europese privaatrecht en proberen daarbij te voorzien of zich in de toekomst nog meer belangrijke wijzigingen zullen voordoen. Omdat het Unierecht in vergelijking met het EVRM de laatste decennia de grootste stempel heeft gedrukt op het privaatrecht, zal het grootste deel van de bijdragen Unierechtelijke ontwikkelingen tot uitgangspunt nemen.

Het themanummer begint met vier algemene en overkoepelende bijdragen. Stein bijt het spits af en vraagt zich af of de figuur van richtlijnen van Unierecht voor het nationale én Unierechtelijke privaatrecht als 'gamechanger(s)' moeten worden aangemerkt. Meer in het bijzonder wordt hier ingegaan op de vraag of en in hoeverre rechtssubjecten bescherming kunnen ontlenen aan niet, niet-juist en/of nietvolledig geïmplementeerde bepalingen uit Europese richtlijnen. De conclusie is dat het fenomeen van de Unierechtelijke richtlijn een echte gamechanger is, zeker voor het Unierecht zélf. Ook Aronstein richt zich op een algemeen en overkoepelend thema: het effectiviteitsbeginsel en het beginsel van effectieve rechtsbescherming. Beide beginselen vormen het fundament van de doorwerkingsvormen van Unierecht in privaatrechtelijke rechtsverhoudingen. Aronstein bespreekt onder meer de wijze waarop private partijen het Unierecht kunnen inroepen tegen een andere private partij, welke voorwaarden worden gesteld aan civiele remedies en hoe andere beginselen hierdoor soms beperking ondervinden. Maar zijn deze beginselen ook echte gamechangers?

Emaus en Hoops verbreden de blik van het pure Unierecht naar grondrechten in het algemeen, die besloten liggen in het EVRM, maar ook in het EU-Handvest. Beiden schrijven een overkoepelende bijdrage over de invloed van Europese grondrechten op het (nationale) privaatrecht. Emaus buigt zich over recente ontwikkelingen op het gebied van de doorwerking van de Europese grondrechten in het verbintenissenrecht. Zij concludeert dat Europese grondrechten sterker dan ooit gamechangers (kunnen) zijn. De rechten in het EVRM zijn gamechangers omdat zij aanleiding kunnen geven tot een vorm van genoegdoening, óók of juist als de nationale rechter oordeelt dat op basis van het nationale onrechtmatigedaadrecht geen schadevergoeding bestaat. De grondrechten in het EU-Hand- 
vest, waarvan de doorwerking nog volop in ontwikkeling is, kunnen wat haar betreft eveneens gamechangers zijn. Hoops richt zich op de doorwerking van grondrechten in het goederenrecht, en meer specifiek op de Pye-zaak van het Europees Hof voor de Rechten van de Mens. Daarin werd beslist dat het Engelse equivalent van verjaringsverkrijgingen niet in strijd was met art. 1 Eerste Protocol bij het EVRM, waarin het recht op het ongestoorde genot van het eigendomsrecht is neergelegd. De auteur is kritisch op dit verstrekkende arrest, en betoogt dat een meer genuanceerde beoordeling onbillijke van billijke verjaringsverkrijgingen had kunnen scheiden. Dan was de Pye-zaak pas echt een gamechanger geworden.

De bijdragen die volgen, zijn meer gericht op specifieke onderwerpen of rechtsgebieden. Zo vraagt Bassi zich af of de buitencontractuele aansprakelijkheid van particulieren wegens schending van het Unierecht door andere particulieren, zoals voor art. 101 VWEU is aanvaard in de 'klassieke' Couragezaak, een substantiële wijziging teweeg heeft gebracht. Als een grote schok kon de Courage-zaak niet zijn gekomen, zo concludeert hij, omdat deze 'horizontale aansprakelijkheid' eigenlijk gewoon volgt uit (de systematiek van) art. 101 VWEU. Wel is het de vraag of het $\mathrm{HvJ}$ in de toekomst ook buitencontractuele aansprakelijkheid voor schending van andere Unierechtelijke normen zal aanvaarden.

Van Beek \& Schelhaas richten zich op het consumentenkooprecht, waar de EU een grote invloed op heeft (gehad) en een groot aantal richtlijnen voor heeft uitgevaardigd. De auteurs analyseren onder meer de regelingen van Unierechtelijke origine inzake koop op afstand, de conformiteitsregeling en de daarbij horende remedies, alsmede de klachtplicht bij consumentenkoop. $\mathrm{Zij}$ zien verschillende regels die de spelregels in het (Nederlandse) kooprecht aanzienlijk hebben veranderd en dus als gamechanger(s) kunnen worden gekenschetst. De auteurs verwachten in de toekomst meer aanzienlijke wijzigingen in het consumentenkooprecht en denken dat hierbij vooral elektronische ontwikkelingen de katalysator zullen zijn.

Boersen \& De Jong richten zich op de privaatrechtelijke handhaving van het mededingingsrecht, bij de ontwikkeling waarvan het Unierecht een belangrijke rol heeft gespeeld. Meer specifiek bespreken zij het recente Skanska-arrest van het HvJ, waarin het Hof oordeelde dat het bij kartelinbreuken ook de inbreukplegende 'onderneming' is die civielrechtelijk aansprakelijk is. Maar omdat de onderneming in het privaatrecht geen rechtssubject is, is het de vraag welke rechtspersonen behorende tot 'de onderneming' als schadeplichtig kunnen worden aangewezen. Een gamechanger die - net als eerdere arresten van het HvJ op dit gebied - de rol van het nationale recht van de lidstaten verandert?

Het themanummer besluit met een bijdrage van Van der JagtVink over een onderwerp dat recent onder invloed van het Unierecht een hoge vlucht heeft genomen: privacy-inbreuken en de vraag of en in hoeverre schadevergoeding kan worden gevorderd als gevolg van inbreuken op de Europese Algemene Verordening Gegevensbescherming (AVG). De auteur beantwoordt aan de hand van enkele actuele voorbeelden de vraag of de mogelijkheden om schadevergoeding te vorderen wezenlijk zijn gewijzigd door de komst van de AVG. Zal de AVG gaan leiden tot een stortvloed van privacyclaims of is het effect van de nieuwe wetgeving in de praktijk beperkt? Met andere woorden: is ook hier sprake van een gamechanger?

De vraag of de in dit nummer besproken ontwikkelingen als gamechanger moeten worden aangemerkt, richt zich op het verleden. Kijken wij vooruit, dan is het vooral de vraag of de hier besproken ontwikkelingen zullen doorzetten, afzwakken, een andere draai zullen nemen of zelfs tot een einde zullen komen. Met dit themanummer heeft de lezer in ieder geval voldoende materiaal in handen om deze ontwikkelingen ook in de toekomst op de voet te kunnen volgen. 